\title{
Concentrated autologous bone marrow aspirate transplantation treatment for corticosteroid-induced osteonecrosis of the femoral head in systemic lupus erythematosus
}

\author{
Tomokazu Yoshioka • Hajime Mishima • \\ Hiroshi Akaogi • Shinsuke Sakai • Meihua Li • \\ Naoyuki Ochiai
}

Received: 20 March 2010 /Revised: 7 May 2010 /Accepted: 9 May 2010/Published online: 29 May 2010

(C) The Author(s) 2010. This article is published with open access at Springerlink.com

\begin{abstract}
The purpose of this study was to evaluate concentrated autologous bone marrow aspirate transplantation (CABMAT) treatment for corticosteroid-induced osteonecrosis of the femoral head (ONFH) in systemic lupus erythematosus (SLE). Bone marrow was aspirated from iliac crests, concentrated on a conventional manual blood bag centrifugation technique that is used to extract buffy coats and then injected into nine hips with drilling. The mean number of nucleated cells for transplantation was $5.32 \times 10^{7}$ cells $/ \mathrm{ml}$. This cell concentration was significantly higher after concentration, and the mean concentration ratio was 5.5. At follow-up (minimum: three years), significant improvement in pain and Harris Hip Score was observed.
\end{abstract}

\footnotetext{
T. Yoshioka $\cdot$ H. Mishima $(\bowtie) \cdot H$. Akaogi $\cdot$ S. Sakai $\cdot$ M. Li $\cdot$

N. Ochiai

Department of Orthopaedic Surgery,

Control of Musculoskeletal System,

Advanced Biomedical Applications,

Graduate School of Comprehensive Human Sciences,

University of Tsukuba,

1-1-1 Tennodai,

Tsukuba, Ibaraki 305-8575, Japan

e-mail: hmishima@md.tsukuba.ac.jp

T. Yoshioka

e-mail: tymd99@gmail.com

H. Akaogi

e-mail: coo.akaogi@air.ocn.ne.jp

S. Sakai

e-mail: Shinsuke33@aol.com

M. Li

e-mail: limeihua512@yahoo.co.jp

N. Ochiai

e-mail: nochiai@md.tsukuba.ac.jp
}

For eight of nine hips, we successfully preserved the femoral head. However, one hip required total hip arthroplasty 45 months after the operation. CABMAT using our centrifugation technique is an effective, safe and low-cost procedure of therapeutic osteogenesis for corticosteroidinduced ONFH in SLE.

\section{Introduction}

Systemic lupus erythematosus (SLE) is a chronic, inflammatory, multisystem autoimmune disease of unknown aetiology that predominantly affects young people [1]. Osteonecrosis $(\mathrm{ON})$ is a common musculoskeletal complication in SLE with high-dose corticosteroid therapy [2]. In Japan, approximately $54 \%$ of patients with idiopathic ON of the femoral head (ONFH) have received corticosteroid therapy and $31 \%$ of patients with corticosteroid-induced ONFH have SLE [3]. The clinical course of ON is unpredictable, but radiographic evaluation has demonstrated that small osteonecrotic lesions may heal, remain stable without progression or eventually cause significant joint damage [4]. However, large lesions, even those that are asymptomatic, may result in femoral head collapse and pain from the fracture and secondary osteoarthritis [5].

It has been reported that failed or delayed fracture healing and ONFH can be repaired with autologous bone marrow aspirate (BMA) transplantation [6, 7]. Hernigou et al. [8] first reported the results of a prospective study on the benefits of autologous bone marrow grafting. Gangji et al. [9] first reported the results of a controlled, double-blind trial on the efficacy of autologous bone marrow cell implantation. Both 
groups used a cell separator to sort and concentrate only bone marrow nucleated cells for transplantation and concluded that a concentrated BMA transplantation improved femoral head preservation in the early stages of ONFH.

Our group developed a simple one-step concentration procedure using a conventional manual blood bag centrifugation technique instead of a cell separator [10]. This procedure concentrates platelets in the BMA in addition to bone marrow nucleated cells. We found that transplantation of this product, a procedure named concentrated autologous bone marrow aspirate transplantation (CABMAT), was able to alter the natural history of ONFH [11]. In this retrospective study, we have analysed the results of our CABMAT study of patients with corticosteroid-induced ONFH with SLE.

\section{Materials and methods}

All procedures were approved by an Institutional Ethics Review Committee of the University of Tsukuba. Informed consent was obtained from all individuals who participated in this study prior to the operation.

\section{Patients}

Between April 2003 and May 2008, 85 patients (131 hips) with ONFH were treated with CABMAT. Of the 131 hips, 76 hips in 42 patients (49.4\%) had corticosteroid-induced ONFH, and 32 hips in 18 patients (42.9\%) had corticosteroid-induced ONFH with SLE. In this series, nine hips in six patients (33.3\%) with SLE, who had been followed for three years or more, were examined retrospectively.

Table 1 displays patient clinical profiles. All subjects were women with an average age at the time of CABMAT of 31.5 years (range: $16-52$ years). Among the six patients, two had hyperlipidaemia and two had antiphospholipid syndrome. The mean follow-up period was 41 months (range: 37-53 months). Patients underwent follow-up examination every three months after the CABMAT procedure. The endpoint of evaluation was set as the time point at which the patient required additional surgery (total hip arthroplasty, THA).

\section{Diagnosis of SLE and ONFH}

All patients fulfilled the revised criteria for SLE established by the American Rheumatism Association [12]. The diagnosis, classification and staging of ONFH were based on the 2001 Japanese Orthopaedic Association (JOA) classification using anteroposterior (AP) and lateral plain radiographs or magnetic resonance imaging (MRI) scans [13]. Based on these criteria, necrotic lesions were classified into four types by location on T1-weighted or $\mathrm{X}$-ray images. Type A lesions occupy the medial one third or less of the weight-bearing portion. Type B lesions occupy the medial two thirds or less of the weight-bearing portion. Type $\mathrm{C} 1$ lesions occupy more than the medial two thirds of the weight-bearing portion, but do not extend laterally to the acetabular edge. Type C2 lesions occupy more than the medial two thirds of the weight-bearing portion and extend laterally to the acetabular edge. Staging is based on AP and lateral views of the femoral head on Xray images. Stage 1 is defined as the period when there are no specific findings of $\mathrm{ON}$ on X-ray images, although specific findings are observed on MRI, bone scintigram or histological examination. Stage 2 is the period when demarcating sclerosis is observed without collapse of the femoral head. Stage 3 is the period when collapse of the femoral head, including crescent sign, is observed without joint space narrowing. Stage 3 is divided into two substages. In stage $3 \mathrm{~A}$, collapse of the femoral head is less than

Table 1 Clinical profiles of patients

\begin{tabular}{|c|c|c|c|c|c|c|c|c|c|c|c|}
\hline \multirow[t]{3}{*}{ No. } & \multirow[t]{3}{*}{ Sex } & \multirow{3}{*}{$\begin{array}{l}\text { Age } \\
\text { (years) }\end{array}$} & \multirow{3}{*}{$\begin{array}{l}\text { Follow-up period } \\
\text { (months) }\end{array}$} & \multirow{3}{*}{$\begin{array}{l}\text { Operated } \\
\text { side }\end{array}$} & \multirow{2}{*}{\multicolumn{2}{|c|}{ Corticosteroid therapy }} & \multirow{3}{*}{$\begin{array}{l}\text { Associated } \\
\text { disease }\end{array}$} & \multicolumn{4}{|c|}{ Classification } \\
\hline & & & & & & & & \multicolumn{2}{|c|}{$\begin{array}{l}\text { Before } \\
\text { CABMAT }\end{array}$} & \multicolumn{2}{|c|}{$\begin{array}{l}\text { After } \\
\text { CABMAT }\end{array}$} \\
\hline & & & & & $\begin{array}{l}\text { Maximum dose } \\
\text { (mg/day) }\end{array}$ & Pulse & & Type & Stage & Type & Stage \\
\hline 1 & $\mathrm{~F}$ & 33 & 53 & Bil & 60 & - & $\mathrm{HL}$ & $\mathrm{C} 1 / \mathrm{C} 2$ & $1 / 2$ & $\mathrm{C} 1 / \mathrm{C} 2$ & $2 / 2$ \\
\hline 2 & $\mathrm{~F}$ & 33 & 52 & Bil & 1,000 & + & APS & $\mathrm{C} 2 / \mathrm{C} 2$ & $3 \mathrm{~B} / 2$ & $\mathrm{C} 2 / \mathrm{C} 2$ & $3 \mathrm{~B} / 3 \mathrm{~A}$ \\
\hline 3 & $\mathrm{~F}$ & 52 & 45 & $\mathrm{~L}$ & 1,000 & + & HL & $\mathrm{C} 2$ & $3 \mathrm{~B}$ & $\mathrm{C} 2$ & 4 \\
\hline 4 & $\mathrm{~F}$ & 16 & 46 & $\mathrm{~L}$ & 1,000 & + & - & $\mathrm{C} 1$ & 2 & $\mathrm{C} 1$ & 2 \\
\hline 5 & $\mathrm{~F}$ & 37 & 37 & Bil & 60 & - & - & $\mathrm{C} 2 / \mathrm{C} 1$ & $3 \mathrm{~A} / 2$ & $\mathrm{C} 2 / \mathrm{C} 1$ & $3 \mathrm{~A} / 2$ \\
\hline 6 & $\mathrm{~F}$ & 28 & 37 & $\mathrm{R}$ & 1,000 & + & APS & $\mathrm{C} 1$ & 1 & $\mathrm{C} 1$ & 2 \\
\hline
\end{tabular}

$F$ female, Bil bilateral, $L$ left, $R$ right, $H L$ hyperlipidaemia, $A P S$ antiphospholipid syndrome 
$3 \mathrm{~mm}$. In stage 3B, collapse of the femoral head is $3 \mathrm{~mm}$ or greater. Stage 4 is the period when osteoarthritic changes are observed.

Harvesting and concentration of bone marrow aspirates [10]

Under general anaesthesia, bone marrow was aspirated from both anterior iliac crests using a bone marrow harvest needle (Medical Device Technologies, Inc., Gainesville, FL, USA) with $20-\mathrm{ml}$ syringes prefilled with anticoagulant citrate dextrose $(1.5 \mathrm{ml})$ to prevent blood clotting. The contents of each syringe were then transferred into a bag from the bone marrow collection kit (Baxter, Deerfield, IL, USA). The BMA was gravity-filtered through a series of mesh filters with successively smaller diameters and then transferred to a quadruple blood bag (Terumo, Tokyo, Japan) for concentration using the manual blood bag centrifugation technique. The fraction of blood containing the BMA was processed by a twostep centrifugation method (KUBOTA 9800, Kubota, Japan) at room temperature. After inverse centrifugation of the blood bag at $1,200 \mathrm{~g}$ for ten minutes, the erythrocytes were transferred into the satellite bag until the interface between the plasma and the erythrocyte layer was $15 \mathrm{~mm}$ from the bottom of the bag. Next, using high-speed centrifugation at $3,870 \mathrm{~g}$ for seven minutes, plasma was transferred slowly into a satellite bag until approximately $4 \mathrm{~cm}$ of plasma was left on top of the buffy coat layer. This technique reduced the typical $300 \mathrm{ml}$ of BMA to $40 \mathrm{ml}$ to increase its nucleated cell concentration. The time required for this two-step centrifugation was less than one hour.

\section{CABMAT surgical procedure}

Patients were placed in a supine position on a traction table with a $\mathrm{C}$-arm image intensifier. Before transplantation, we typically made three multi-directional holes - central, anteromedial and posterolateral - by percutaneous drilling with a Kirschner wire (diameter $2.7 \mathrm{~mm}$ ) to perforate the interface between the necrotic lesion and healthy bone. After the intraosseous pressure of the femoral head was reduced by drilling, core decompression was performed via the percutaneous technique with a $6.0-\mathrm{mm}$ diameter trephine (Iso Medical Systems, Tokyo, Japan). This instrument was inserted into the centre of the necrotic site through the greater trochanter. Its position in the femoral head and in the necrotic site was monitored with biplane fluoroscopy and transplantation was performed slowly under fluoroscopic control.

Haematological analysis

Haematological analysis was performed according to a previously published method [10]. The numbers of nucleated cells in BMA were determined before and after concentration with an automated haematology analyser (K-4500, Sysmex, Kobe, Japan); the concentration ratio was determined as follows: concentration ratio $=$ number of nucleated cells in BMA after concentration/number of nucleated cells in BMA before concentration.

\section{Clinical evaluation}

Immediately before the procedure and at each follow-up, patients were evaluated using the visual analogue scale (VAS) for pain and the Harris Hip Score (HHS) [14]. The VAS is an objective index for pain, where $100 \mathrm{~mm}$ represents maximum pain, $50 \mathrm{~mm}$ represents intermediate pain and $0 \mathrm{~mm}$ represents no pain. The HHS is an objective index of hip joint function that quantifies the four categories of (1) pain, (2) walking function and activities of daily living, (3) extent of deformity and (4) joint range of motion, with higher values indicating greater functionality. Results were determined by the change in VAS and HHS between preoperative evaluation and the most recent followup evaluation. Clinical outcomes were categorised by HHS results at the most recent follow-up as follows: excellent, 90 100; good, 80-89; fair, 70-79; or poor, less than 70 .

\section{Radiographic evaluation}

AP and lateral X-rays of the affected hip were taken at each clinical evaluation. Radiographic progressions of the femoral head collapse (pre-surgery to the most recent follow-up) were evaluated in hips of each classification and staging [13]. The degree of collapse was measured using a template overlay of circles that increase in 1-mm diameter increments. All radiographs were independently evaluated by three different observers who were specialists in orthopaedic surgery and authorised by the JOA.

\section{Statistics}

The concentrations of nucleated cells before and after the concentration procedure were analysed using the paired $t$ test; VAS and HHS results before CABMAT and the most recent follow-up evaluation after CABMAT were analysed using the Mann-Whitney U test. Data are presented as mean \pm standard deviation (SD). A $p$ value of $<0.05$ was considered statistically significant.

\section{Results}

Patient characteristics

Table 1 shows the clinical profiles of patients. No patients were lost to follow-up. Of the six patients studied, three had 
developed bilateral ONFH, and three had developed unilateral ONFH. Two of the six patients had been treated with high-dose corticosteroid (at least $40 \mathrm{mg} /$ day, or the equivalent dose of prednisolone) and four of six patients had received methylprednisolone pulse treatment.

Preoperatively, four of the nine hips were classified as type $\mathrm{C} 1$ and five were classified as type $\mathrm{C} 2$. Two hips were classified as stage 1 , four hips as stage 2 , one as stage $3 \mathrm{~A}$ and two as stage $3 \mathrm{~B}$. No donor site morbidity was observed, and no infections, fractures, pulmonary embolism, or intraor postoperative neurovascular injuries were found. In postoperative management, patients were non-weightbearing on the affected side for $2-12$ weeks, after which they gradually increased weight-bearing.

Haematological analysis

The mean nucleated cell count of the BMA was $0.99 \pm$ $0.38 \times 10^{7}$ cells $/ \mathrm{ml}$ before concentration and $5.32 \pm 2.08 \times$ $10^{7}$ cells $/ \mathrm{ml}$ after concentration; the mean concentration ratio was $5.5 \pm 1.3$. The number of nucleated cells in BMA was significantly higher after our concentration procedure $(p=0.002$; Fig. 1).

\section{VAS}

The VAS pain score was reduced immediately after the CABMAT procedure in all patients. The mean VAS score was $67 \pm 42 \mathrm{~mm}$ before surgery and $17 \pm 22 \mathrm{~mm}$ at the most recent follow-up exam. The VAS score was reduced significantly after CABMAT ( $p=0.02$; Fig. 2 ).

\section{Harris Hip Score}

The mean HHS was $68 \pm 14$ before surgery and $89 \pm 15$ at the most recent follow-up exam. The mean HHS was improved significantly after the CABMAT procedure ( $p=$ 0.01; Fig. 3).

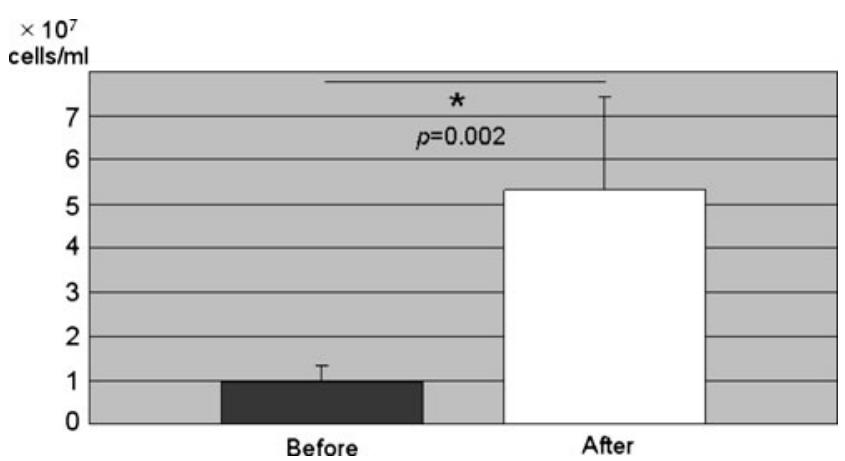

Fig. 1 The number of nucleated cells $\left(\times 10^{7}\right.$ cells $\left./ \mathrm{ml}\right)$ in BMA increased significantly after concentration $(p<0.002)$

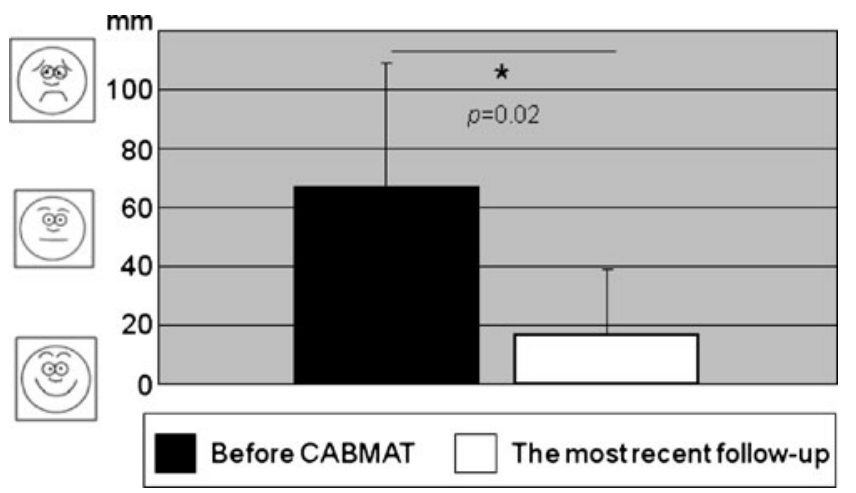

Fig. 2 VAS: the mean VAS score was significantly reduced after CABMAT $(p=0.02)$

Clinical outcomes

Six hips were excellent, two hips were good and one hip was poor as assessed by HHS. Patient 4 was a typical case with an excellent clinical outcome (Fig. 4). THA was necessary in one hip among the three hips operated on after collapse (stage $3 \mathrm{~A}$ and $3 \mathrm{~B}$ ). The hip (patient 3) was classified as type $\mathrm{C} 2$ and stage $3 \mathrm{~B}$; the collapse progressed from stage $3 \mathrm{~B}$ to stage 49 months after CABMAT. The patient suffered from continuous pain of the hip at 37 months post-surgery and THA was performed 45 months after CABMAT.

Radiographic progression after CABMAT

The relationship between the hip classification types or stages before CABMAT and the progression of collapse was evaluated: two of five type $\mathrm{C} 2$ patients, one of four stage 2 patients, and one of two stage $3 \mathrm{~B}$ patients progressed (Fig. 5). Classification types that indicate necrotic lesion size were unchanged between the preoperative evaluation and the most recent follow-up in all of the hips (Table 1).

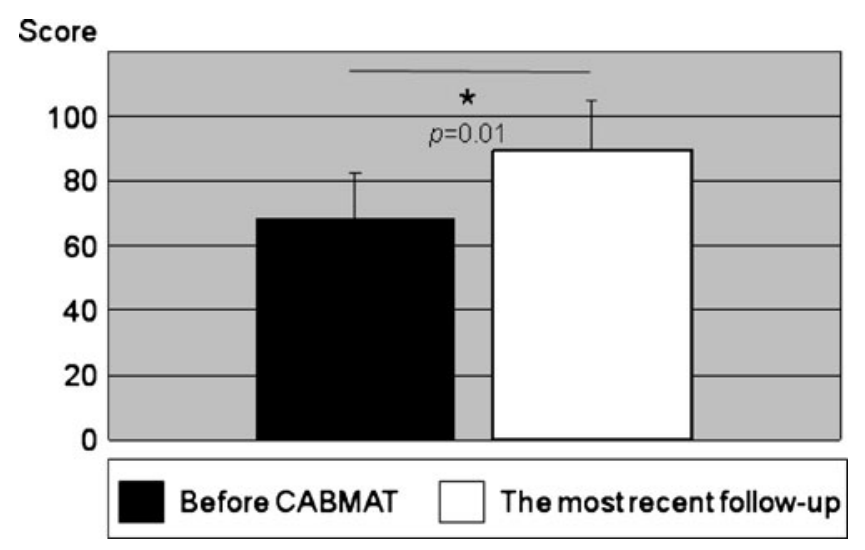

Fig. 3 HHS: the mean HHS score improved significantly after CABMAT $(p=0.01)$ 


\section{Before CABMAT}
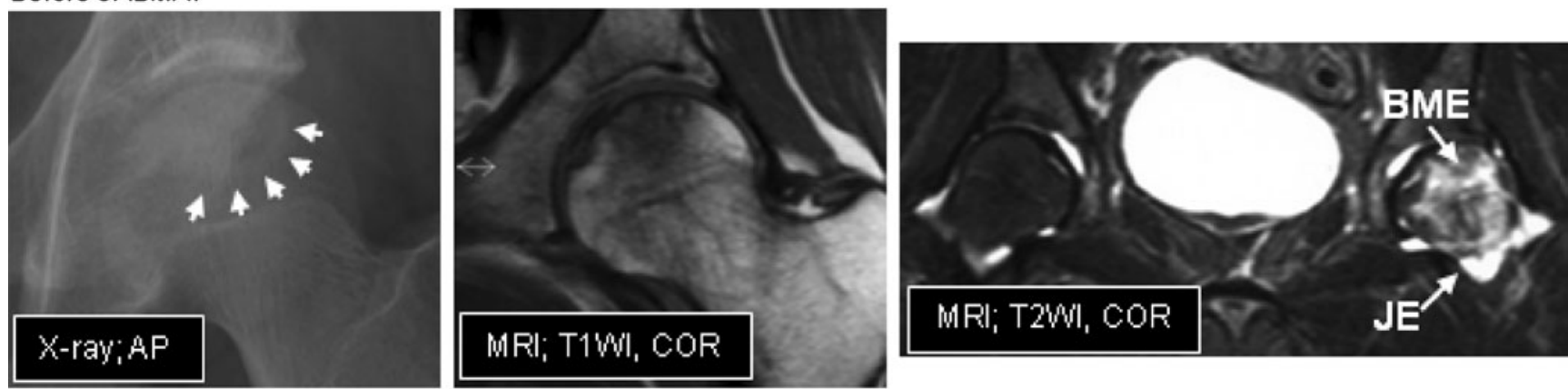

Thirty six-month follow-up
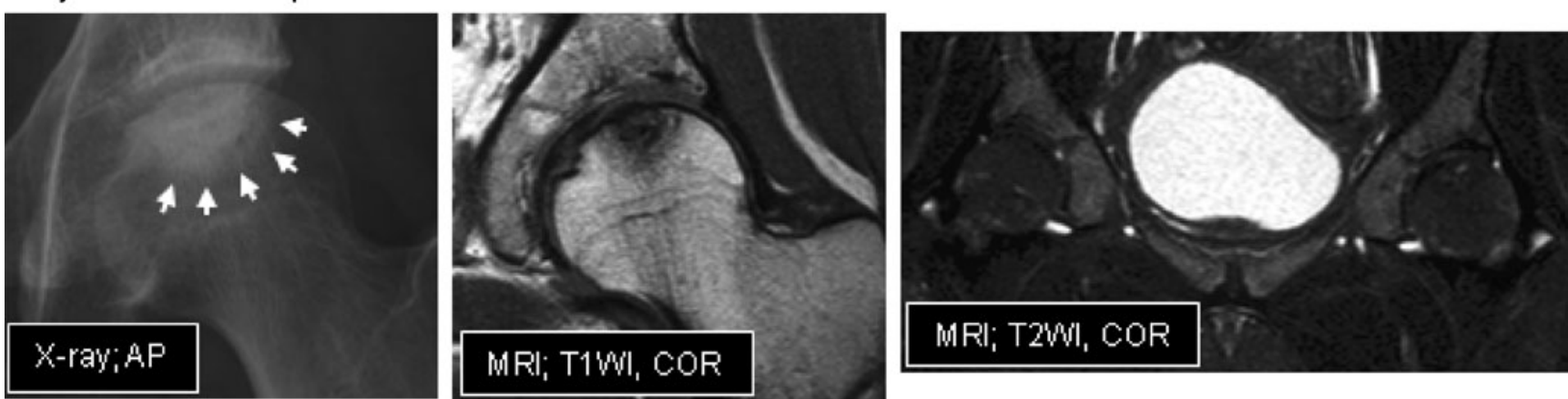

Fig. 4 Representative radiographic images before and after CABMAT. Before CABMAT (upper row), a band pattern was observed on the X-ray (arrows) and changes in the bone marrow signal were observed on MRI scans. Bone marrow oedema $(B M E)$ and joint effusion $(J E)$ were evident on an MRI T2-weighted image. The lower

\section{Discussion}

In this study, we evaluated the efficacy of CABMAT in SLE patients who underwent corticosteroid therapy, a population within which ONFH occurs with the greatest frequency [3]. The results showed that CABMAT significantly improved VAS and HHS results, and eight of nine hips achieved a successful clinical outcome. These results support the utility of CABMAT in preserving the femoral head in patients with corticosteroid-induced ONFH with SLE. However, one of nine hips required THA due to progression of preoperative stage $3 \mathrm{~B}$ to stage 4 (after $>3 \mathrm{~mm}$ collapse), osteoarthritis and continuous pain during row images were obtained during the 3-year follow-up evaluation. Bone consolidation and reduction of the necrotic area were observed on the X-ray and MRI images. Note that bone marrow oedema and joint effusion have disappeared. $A P$ anteroposterior, $C O R$ coronal view, T1WI T1-weighted image, T2WI T2-weighted image

the 45-month follow-up period. These results are consistent with previous studies showing late stage (post-collapse) at presentation and large necrotic lesions in SLE as risk factors for disease progression [15]. Thus, early detection of ONFH in the pre-collapse stage is associated with an improved and more favourable clinical outcome.

The prevalence of ON is much higher in SLE compared to other clinical conditions that require chronic corticosteroid therapy, suggesting that SLE-related features also contribute to the development of ON [15]. Other reports have indicated that the bone marrow microenvironment in SLE can potentially injure osteoblasts and their progenitors, mesenchymal stem cells (MSCs) [5, 15]; however, the exact mechanism by
Fig. 5 Radiographic progression after CABMAT in each classification type and stage ( $n=$ no. of hips)
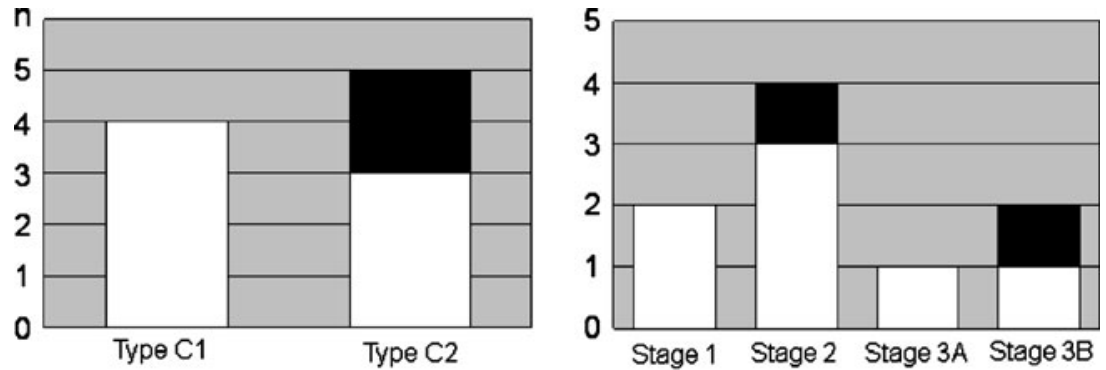
which corticosteroids or pathogenesis of SLE trigger osteonecrosis is unclear. Recently, Hernigou et al. [16] suggested that ONFH may be a disease of bone cells and/or MSCs. MSC numbers and activity have been shown to be depressed in both the haematopoietic and stromal compartments of bone marrow in patients with ONFH. In addition, the number of progenitor cells in patients undergoing corticosteroid therapy was significantly lower than in patients who had a different underlying aetiology [17]. To obtain optimal clinical results, Hernigou et al. [8] suggested that more nucleated cells should be transplanted than the average number of nucleated cells in the femoral head (approximately $3.0 \times 10^{6} / \mathrm{ml}$ ). For patients whose bone marrow nucleated cell density is lower, they suggested that bone marrow injection in combination with growth factors could be a solution in the future.

In this series, nucleated cells were 5.5-fold more concentrated than pre-concentrated BMA and the mean number of transplanted cells was $5.32 \pm 2.08 \times 10^{7}$ cells $/ \mathrm{ml}$. Thus, the number of concentrated cells obtained using our centrifugation technique was much higher than the number of cells suggested for optimal clinical outcome. In addition, the concentrated BMA produced with our method is more heterogeneous than BMA produced with the cell separator method. We speculate that the BMA contains not only osteogenic progenitors, but also other types of nucleated cells, platelet-rich plasma (a rich source of growth factors) [18].

Autologous MSCs appear to exhibit anti-inflammatory, immunomodulatory and tissue-protective "trophic" effects after transplantation for SLE [19]. These results indicate that local transplantation of BMA could alter the pathophysiological mechanisms of SLE in the necrotic site. Additional studies are also needed to evaluate clinical results through long-term follow-up.

Another possible mechanism for the therapeutic effect of CABMAT is via core decompression with multiple drillings [20]. Core decompression decreases the intraosseous pressure and opens a channel into the necrotic area, which is thought to alter the natural history of necrosis and encourage revascularisation and repair. We drilled three channels to induce migration of nucleated cells and platelets to the necrotic site for bone regeneration [21]. The channels also reduced intraosseous pressure on the femoral head and relieved the pain associated with ONFHinduced bone marrow oedema or joint effusion.

In conclusion, we report on a minimum three year followup of CABMAT for corticosteroid-induced ONFH with SLE. In order to confirm the efficacy of CABMAT, results from BMA transplantation carried out using our centrifugation method or by a cell separator in a randomised, matched, controlled prospective study need to be compared. This technique required no special devices and may be an easy-touse, minimally invasive biological joint-preserving procedure for the early stages of corticosteroid-induced ONFH with SLE.
Acknowledgements There was no external funding source for this study.

Conflict of interest The authors declare that they have no conflicts of interest.

Open Access This article is distributed under the terms of the Creative Commons Attribution Noncommercial License which permits any noncommercial use, distribution, and reproduction in any medium, provided the original author(s) and source are credited.

\section{References}

1. Lane NE (2006) Therapy insight: osteoporosis and osteonecrosis in systemic lupus erythematosus. Nat Clin Pract Rheumatol $2: 562-569$

2. Abu-Shakra M, Buskila D, Shoenfeld Y (2003) Osteonecrosis in patients with SLE. Clin Rev Allergy Immunol 25:13-24

3. Fukushima W, Hirota Y, Fujioka M, Kubo T, Tamakoshi A, Nagai $M$ (2007) The final report of the national epidemiologic investigation for idiopathic osteonecrosis of the femoral head. In: Kubo $\mathrm{T}$ (ed) Annual report of Japanese investigation committee for intractable diseases, idiopathic osteonecrosis of the femoral head, under the auspices of Ministry of Health and Welfare:1-5 (in Japanese)

4. Zhao FC, Li ZR, Zhang NF, Wang BL, Sun W, Cheng LM, Liu $\mathrm{ZH}$ (2009) Lesion size changes in osteonecrosis of the femoral head: a long-term prospective study using MRI. Int Orthop. doi:10.1007/s00264-009-0829-7

5. Egol KA, Jazrawi LM, DeWal H, Su E, Leslie MP, Di Cesare PE (2001) Orthopaedic manifestations of systemic lupus erythematosus. Bull Hosp Jt Dis 60:29-34

6. Connolly JF, Shindell R (1986) Percutaneous marrow injection for an ununited tibia. Nebr Med J 71:105-107

7. Hernigou P, Poignard A, Manicom O, Mathieu G, Rouard H (2005) The use of percutaneous autologous bone marrow transplantation in nonunion and avascular necrosis of bone. $\mathrm{J}$ Bone Joint Surg Br 87:896-902

8. Hernigou P, Beaujean F (2002) Treatment of osteonecrosis with autologous bone marrow grafting. Clin Orthop Relat Res 405:14-23

9. Gangji V, Hauzeur JP, Matos C, De Maertelaer V, Toungouz M, Lambermont M (2004) Treatment of osteonecrosis of the femoral head with implantation of autologous bone-marrow cells. A pilot study. J Bone Joint Surg Am 86:1153-1160

10. Sakai S, Mishima H, Ishii T, Akaogi H, Yoshioka T, Uemura T, Ochiai $\mathrm{N}$ (2008) Concentration of bone marrow aspirate for osteogenic repair using simple centrifugal methods. Acta Orthop 79:445-448

11. Akaogi H, Mishima H, Sakai S, Yoshioka T, Ishii T, Ochiai N (2007) Treatment of osteonecrosis of the femoral head with implantation of autologous bone marrow cells. The short term results. Hip Joint 33:40-46 (in Japanese)

12. Aranow C, Zelicof S, Leslie D, Solomon S, Barland P, Norman A, Klein R, Weinstein A (1997) Clinically occult avascular necrosis of the hip in systemic lupus erythematosus. J Rheumatol 24:2318-2322

13. Sugano N, Atsumi T, Ohzono K, Kubo T, Hotokebuchi T, Takaoka K (2002) The 2001 revised criteria for diagnosis, classification, and staging of idiopathic osteonecrosis of the femoral head. J Orthop Sci 7:601-605

14. Harris WH (1969) Traumatic arthritis of the hip after dislocation and acetabular fractures: treatment by mold arthroplasty. An endresult study using a new method of result evaluation. J Bone Joint Surg Am 51:737-755 
15. Rascu A, Manger K, Kraetsch HG, Kalden JR, Manger B (1996) Osteonecrosis in systemic lupus erythematosus, steroid-induced or a lupus-dependent manifestation? Lupus 5:323-327

16. Hernigou P, Beaujean F, Lambotte JC (1999) Decrease in the mesenchymal stem-cell pool in the proximal femur in corticosteroidinduced osteonecrosis. J Bone Joint Surg Br 81:349-355

17. Gao YS, Zhang CQ (2010) Cytotherapy of osteonecrosis of the femoral head: a mini review. Int Orthop. doi:10.1007/s00264-0101009-5

18. Sakai S, Mishima H, Akaogi H, Yoshioka T, Ishii T, Ochiai N (2006) Concentration of angiogenic and osteogenic growth factors in peripheral blood and bone marrow blood of osteonecrosis patient. Osteoarthritis Cartilage 14(Suppl B):S76-S77

19. Caplan AI (2009) Why are MSCs therapeutic? New data: new insight. J Pathol 217:318-324

20. Mont MA, Fairbank AC, Petri M, Hungerford DS (1997) Core decompression for osteonecrosis of the femoral head in systemic lupus erythematosus. Clin Orthop Relat Res 334:91-97

21. Lee HS, Huang GT, Chiang H, Chiou LL, Chen MH, Hsieh CH, Jiang CC (2003) Multipotential mesenchymal stem cells from femoral bone marrow near the site of osteonecrosis. Stem Cells 21:190-199 